\title{
Images
}

\section{How to diagnose a Canadian: a case of foreign body ingestion}

\author{
Jeff H. Yoo, MD; Hans Rosenberg, MD, CCFP(EM)
}

An 18-year-old female presented to the emergency department (ED) complaining of a foreign body (FB) sensation in her throat after drinking heavily the previous night. While taking her last "shot" of liquor, she felt a cool object in her mouth. Assuming that it was an ice cube, she "took it down" and immediately felt the object get stuck in her throat. She had no respiratory complaints and was able to tolerate solid foods with mild discomfort but no significant issues. The patient's physical examination was unremarkable for signs of tracheoesophageal obstruction.

After reviewing the patient's soft tissue radiograph of the neck, the staff physician and medical student agreed that the final diagnosis was "Canadian." Finding a radiopaque maple leaf-shaped FB in the patient's esophagus (Figure 1), the gastroenterology service was called and performed upper endoscopy with removal of the metallic object. A minor ulcer was found; however, no other sequelae resulted from the ingestion. The patient was sent home on a clear fluid diet to advance as tolerated.

Esophageal FBs require urgent management because of potentially life-threatening complications. Plain radiography is indicated in all patients with a history suggestive of FB ingestion. One study found that plain soft tissue radiographs of the neck were $86 \%$ sensitive for $\mathrm{FB}$ ingestion. ${ }^{1-3}$ Symptomatic patients with a clear history of FB ingestion, a normal physical examination, and normal initial radiographs should be considered for endoscopy to rule out the presence of an FB., ${ }^{4,5}$

Competing interests: None declared.

Keywords: foreign body, ingestion, Canadian, radiograph, radiography

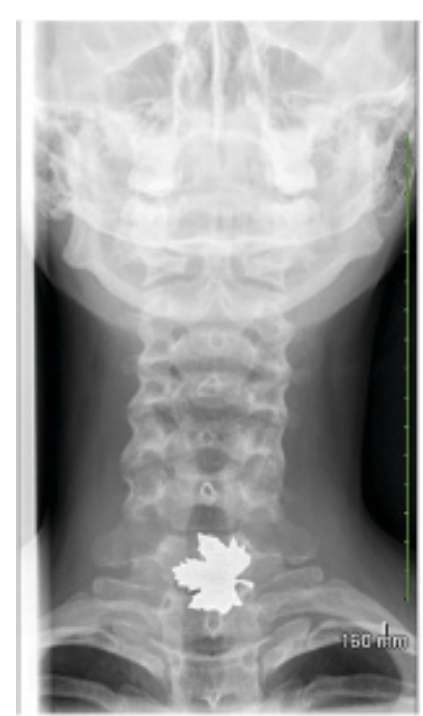

Figure 1. Soft tissue radiograph of the neck (AP) shows a radiopaque maple leaf-shaped foreign body lodged at the level of C7-T1.

\section{REFERENCES}

1. Wainer DL, Ouanounou S, Donnelly LF, et al. Utility of radiographs in the evaluation of paediatric upper airway obstruction. Ann Otol Rhinol Laryngol 1999;108:378-83.

2. Karnawal A, Ho EC, Molony N. Lateral soft tissue neck xrays: are they useful in management of upper aero-digestive tract foreign bodies? F Laryngol Otol 2008;122:845-7.

3. Silva AB, Muntz HR, Clary R. Utility of conventional radiography in the diagnosis and management of paediatric airway foreign bodies. Ann Otol Rhinol Laryngol 1998;107:834-8.

4. Zerella JT, Dimler M, McGill LC, et al. Foreign body aspiration in children: value of radiography and complications of bronchoscopy. 7 Pediatr Surg 1998;33:1651-4, doi:10.1016/ S0022-3468(98)90601-7.

5. Akazawa Y, Watanabe S, Nobukiyo S, et al. The management of possible fishbone ingestion. Auris Nasus Larynx 2004;31:413-6.

From the Department of Emergency Medicine, University of Ottawa, Ottawa, ON.

Correspondence to: Dr. Jeff Yoo, Department of Emergency Medicine, University of Ottawa, Ottawa, ON K1Y 1J8; jeffhyoo@gmail.com.

This article has been peer reviewed.

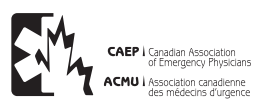

